冰芯与寒区环境开放实验室和冻土工程国家重点实验室及花石峡冻土站共同资助项目.

参 考 文 献

1 Khalil M A K, Shearer M J, Rasmussen R A. Methane sources in China: historical and current emissions. Chemosphere, 1993, 26: 127 142

2 赵魁义, 刘兴土. 湿地研究的现状与展望. 见: 陈宜瑜主编. 中国湿地研究. 长春: 吉林科学技术出版社, 1995. 1 9

3 郑 度, 王秀红, 申元村. 青藏高原湿地初探. 见: 陈宜瑜主编. 中国湿地研究. 长春: 吉林科学技术出版社, 1995. 236 240

4 徐 琪, 蔡 立, 董元华. 论我国湿地的特点、类型与管理. 见: 陈宜瑜主编. 中国湿地研究. 长春: 吉林科学技术出版 社, 1995. 24 33

5 王明星，戴爱国，黄 俊. 中国 $\mathrm{CH}_{4}$ 排放量的估算. 大气科学, 1993, 17( 1): 52 64

6 蔡祖聪. 中国稻田 $\mathrm{CH}_{4}$ 排放估计. 见: 陈宜瑜主编. 中国湿地研究. 长春: 吉林科学技术出版社, 1995. 79 85

7 陈伟烈. 中国湿地植被类型、分布及其保护. 见: 陈宜瑜主编. 中国湿地研究. 长春: 吉林科学技术出版社, 1995. $55 \sim 62$

8 刘兴土. 三江平原湿地及其合理利用与保护. 见: 陈宜瑜主编. 中国湿地研究. 长春: 吉林科学技术出版社, 1995. 108 117

\title{
华北克拉通太古宙陆核氧同位素 $\left(\delta^{17} \mathbf{O}-\delta^{18} \mathbf{O}\right)$ 组成不均一性的初步研究
}

\section{刘建忠张福勤 ${ }^{(4)}$ 李春来 王世杰 Ian Franchi ${ }^{(\text {(U) }}$ Robert Hutchison Colin Pillinger ${ }^{(\text {(M) }}$}

( 中国科学院地球化学研究所, 贵阳 550002; 4)中国科学院地球物理研究所, 北京 100101;

(偦Planetary Science Research Institute, The Open University, Walton Hall, Milton Keynes MK7 6AA, U. K. ;

Department of Mineralogy, The Natural History Museum, Cromwell Road, London SW7 5BD, U. K. )

摘要 通过对华北克拉通不同陆核斜长角闪岩类氧同位素组成测试和分析, 表明: ( ) 来自 不同陆核的岩石氧同位素数据所构成的演化线都平行于地月演化线, 说明这些陆核演化的母 体属于太阳系物质; ( ) 不同陆核的氧同位素组成演化线斜率相近, 截距不同, 说明华北克拉 通太古宙不同陆核起源于氧同位素组成不均一的古地幔源.

关键词 华北克拉通 氧同位素 $\left(\delta^{17} \mathbf{O} \delta^{18} \mathbf{O}\right)$ 不均一性

基于氧同位素的研究, Clayton 等人 ${ }^{[1]}$ 发现, 所有的地球和月球的样品均落在斜率近于 0.5 的直线上 $(0.52)$. 起源于太阳系的陨石, 其氧同位素演化线平行于地月线(即斜率相同而截距 不同), 陨石中若含有太阳系外物质 (如 $\mathrm{C}_{2}$ 和 $\mathrm{C}_{3}$ 型碳质球粒陨石中的白色包体), 则构成与地 月线斜交的直线, 这样可以利用氧同位素组成演化特征的差异将陨石划分为 6 大类 ${ }^{2]}$. 具有 不同氧同位素组成的陨石来源于不同的母体 ${ }^{[3]}$, 因为没有任何一个氧同位素存在已知的天然 
放射性母体, 同时也未曾观测到由高能粒子照射所引起的其他核效应. 因此, 如 $\mathrm{C}_{2}$ 和 $\mathrm{C}_{3}$ 型碳 质球粒陨石中的白色包体类物质出现的氧同位素组成演化异常可以认为是原始化学不均一性 引起的, 这已成为判别太阳系物质来源的重要依据.

华北克拉通作为中国最大的古老地壳出露区, 对于研究早期陆壳的起源和演化具有得天 独厚的条件. 诸多学者对其岩石、构造、矿产和演化历史均进行了长期不解的研究, 不少学者 对其矿产分布的不均匀性和早期地球化学不均一性做了成因探讨 ${ }^{[4 \sim 6]}$. 但鉴于对利用 $\delta^{17} \mathrm{O}-$ $\delta^{18} \mathrm{O}$ 关系研究早期地球化学不均一性的重视程度不够, 国内、外甚少利用 $\delta^{17} \mathrm{O}-\delta^{18} \mathrm{O}$ 研究早期 大陆地壳演化源区的性质. 本文在吸收陨石学研究成果 ${ }^{[7]}$ 的基础上, 首次利用氧同位素 $\left(\delta^{17} \mathrm{O}-\delta^{18} \mathrm{O}\right)$ 对华北克拉通太古宙上地幔的不均一性及其起因进行了探讨, 结果表明华北克拉 通不同陆核间的氧同位素 $\left(\delta^{17} \mathrm{O}-\delta^{18} \mathrm{O}\right)$ 组成有系统差异, 说明这些陆核母体均由起源于太阳系 的、化学组成不均一的母体演化而来.

\section{1 样品及分析测试方法和技术}

本文所用样品均为来源于上地幔的基性岩石( 斜长角闪岩类), 分别采自东胜陆核( DSCN) 的包头大青山杂岩( DN97-1)、山西阳高的怀安杂岩( DY97-1-1, DY97-1-2)、环渤海陆核( CBCN) 的冀东青龙-王厂剖面(HJ97-1-1, HJ97-1-2) 和曹庄杂岩(HJ97-2-1, HJ97-2-2) 以及临汾陆核 (LFCN) 的阜平杂岩(LF97-1-1, LE97-1-2) ${ }^{[8]}$, 其具体位置除冀东外已由 GPS 定位仪精确测定(表 1). 根据区域同位素年代学研究资料推断, 其中代表东胜陆核的包头地区的样品年龄大致为 $2.6 \mathrm{Ga}^{[9]}$, 阳高地区的样品形成年龄大致为 $2.6 \mathrm{Ga}^{[10]}$, 采自阜平地区的样品年龄约 $2.8 \mathrm{Ga}^{[11]}$, 采自青龙-王厂剖面的样品, 年龄大致为 $2.786 \mathrm{Ga}^{[12]}$, 而采自冀东迁安曹庄杂岩的样品年龄达 到 $3.5 \mathrm{Ga}^{[13,14]}$.

表 1 华北克拉通不同陆核样品的位置及氧同位素组成

\begin{tabular}{|c|c|c|c|c|c|c|}
\hline 样品编号 & 采样位置 & 经纬度 & 岩石名称 & $8^{17} \mathrm{O}_{\text {swow }} / \%$ & $\delta^{18} \mathrm{O}_{\text {suow }} / \%$ & 年龄值/ Ga \\
\hline DN97-1 & 内蒙包头哈达门沟 & $\begin{array}{l}\text { N: } 40^{\circ} 43^{\prime} 59.6^{\prime \prime} \\
\text { E: } 109^{\circ} 37^{\prime} 42.2^{\prime \prime}\end{array}$ & 斜长角闪岩 & 3. 264 & 5.701 & 2.6 \\
\hline DY97-1-1 & & $\mathrm{N}: 40^{\circ} 25^{\prime} 11.5^{\prime \prime}$ & & 3.576 & 6.220 & 2.6 \\
\hline DY97-1-2 & 山西阳高县东南 & E: $114^{\circ} 17^{\prime} 44.8^{\prime \prime}$ & 斜长角闪岩 & 3. 551 & 6. 201 & \\
\hline HJ97-1-1 & & & & 4. 040 & 7. 210 & \\
\hline HJ97- 1-2 & 河北青龙-王厂 & & 斜长角闪岩 & 4. 144 & 7. 403 & 2.786 \\
\hline HJ97-2-1 & & & & 4. 227 & 7. 544 & \\
\hline HJ97-2-2 & 河北迁安曹庄 & & 斜长角闪岩 & 4. 168 & 7. 432 & 3.5 \\
\hline LF97-1-2 & & $\mathrm{N}: 38^{\circ} 52^{\prime} 21.5^{\prime \prime}$ & & 3.551 & 6. 297 & \\
\hline LF $97-1-2$ & 河北阜平西 & E: $114^{\circ} 02^{\prime} 21.4^{\prime \prime}$ & 斜长角闪岩 & 3.715 & 6.552 & 2.8 \\
\hline
\end{tabular}

样品的氧同位素分析是在英国开放大学完成的. 样品在 $0.2 \mathrm{~atm}\left(1 \mathrm{~atm}=10^{5} \mathrm{~Pa}\right) \mathrm{BrF}_{5}$ 的 环境下用散焦 $\mathrm{CO}_{2}$ 激光加热, 以释放氧, 随后氧气被纯化, 再用于 VG Isotech PRISM 园质谱仪分 析. 分析精度对于 $\delta^{17} \mathrm{O}$ 和 $\delta^{18} \mathrm{O}$ 都是 $\pm 0.06 \%$ 。测试数据如表 1 .

\section{2 结果与讨论}

由于 ${ }^{16} \mathrm{O}$ 和 ${ }^{18} \mathrm{O}$ 之间质量数相差 2 , 许多研究业已证实在复杂的地质过程中, ${ }^{16} \mathrm{O}$ 和 ${ }^{18} \mathrm{O}$ 之间 有明显的同位素分馏现象, 适合于示踪地质、地球化学过程. 而 ${ }^{17} \mathrm{O}$ 和 ${ }^{18} \mathrm{O}$ 的质量相差仅 1 , 在 地质过程中同位素分馏应很小, 故而, 利用 $\delta^{17} \mathrm{O}-\delta^{18} \mathrm{O}$ 相关图来判别早期不同陆核的地幔源区 
化学不均一性具有一定的可行性.

将华北克拉通不同陆核氧同位素组成数据 投影到 $\delta^{17} O-\delta^{18} O$ 图上(图 1), 从图中可见不同 陆核所采样品所构成的趋势线均近于平行地月 线, 也就是说其斜率基本相同, 但截距却有一定 的差异, 截距的不同代表陆核氧同位素组成和 演化趋势的不同.

特别需要指出的是冀东地区的样品, 曹庄 杂岩与青龙-王厂剖面所在的遵化-青龙绿岩带 形成年龄相差近 $0.8 \mathrm{Ga}$, 但两个地区的 4 个数 据点构成一条平行于地月演化线的直线 (斜率 为 0.56 ), 验证了氧同位素组成的演化特征 (即 演化的线性关系) 并没有随时间而发生变化. 华北克拉通其他陆核氧同位素组成演化特征的 差异应反映对区域古地幔源区同位素组成不均

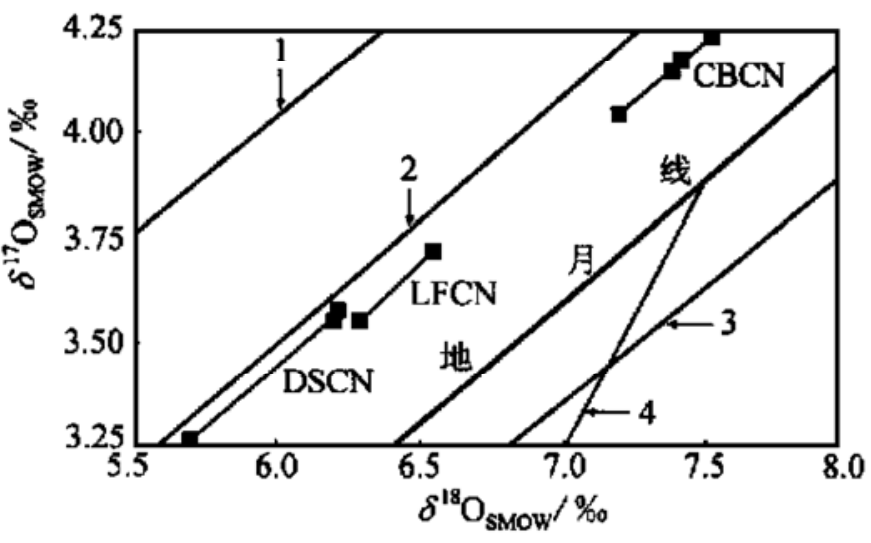

图 1 华北克拉通不同陆核的氧同位素组成 图中 $\mathrm{L}+\mathrm{LL}$ 群球粒陨石、 $\mathrm{H}$ 群球粒陨石与 $\mathrm{C}_{2}, \mathrm{C}_{3}$ 的白色包 体和钻长辉长无球粒陨石演化线引自文献[ 1 3]. DSCN 的斜率为 0.5886 , 截距为 $0.0918 ; \mathrm{CBCN}$ 斜率为 0.5617 , 截距 为 $0.0103 ; \mathrm{LFCN}$ 的截距为 0.6431 , 截距为 $0.4988 .1-\mathrm{L}$ 和 LL 群球粒陨石, $2-\mathrm{H}$ 群球粒陨石, $3-\mathrm{E}$ 群球粒陨 石, $4-\mathrm{C}_{2}$ 和 $\mathrm{C}_{3}$ 型球粒陨石中的白色包体 一性的继承导致的,而不是由于壳、幔演化过程

引起的. 不同陆核的 3 条演化线的截距不同反映出其氧同位素组成演化的差异, 这种差异说 明它们可能来源于初始化学组成有异的原始母体.

如图 1 所示所有样品的点都平行于地月演化线, 与其他来源于太阳系物质的其他陨石均 构成一组较好的平行线, 这进一步证实了 Clayton 关于太阳系物质具有平行的氧同位素演化线 的思想, 同时也说明华北太古宙陆核是起源于太阳系本身物质. 图 1 中一个有趣的现象是所 有样品的氧同位素演化线靠近 $\mathrm{H}$ 群球粒陨石, 表明华北克拉通的原始成分接近于 $\mathrm{H}$ 群球粒陨 石.

致谢本文是在欧阳自远先生思想指导下完成的, 并在成文过程中得到了具体的帮助. 本工作为中国科学院 重点项目(编号: KZ9521-J1-413) 和中国科学院重大项目(KZ951-B1-404 及 KZ951-B1-401) 以及国家自然科学基 金( 批准号: 49573194) 的联合资助项目.

\section{参 考 文 献}

1 Clayton R N, Grossman L, Mayeda T K. A component of primitive nuclear composition in carbonaceous meteorites. Science, 1973, 182: $485 \sim 488$

2 Clayton R N, Onuma N, Mayeda T K. A classification of meteorites based on oxygen isotopes. Earth and Planetary Science Letters, 1976, 30: 10 18

3 Clayton R N, Mayeda T K. Oxygen isotopes in eucrites, shergottites, nakhlites, and chassignites. Earth and Planetary Science Letters, 1983, 62: $1 \sim 6$

4 刘建忠, 欧阳自远, 张福勤, 等. 华北克拉通太古宙上地幔不均一性及其起源: 钕同位素证据. 科学通报, 1998 , 43 (20) : 2229 2232

5 李曙光, 张宗清. 华北太古代上地幔钕同位素组成、演化及对该区岩石圈地幔不均一性的制约. 地球化学, 1990(4): 277 285

6 Zhou X, Carlson R W. Isotopic evidence for temporal variability of mantle characteristics beneath the North China fault block. Carnegie 
Inst Wash Year Book, 1982, 81: 505 508

7 欧阳自远. 天体化学. 北京: 科学出版社, 1988. 36 38, 161 246

8 白 瑾, 黄学光, 王惠初, 等. 中国前寒武纪地壳演化(第二版). 北京: 地质出版社, 1996. 12 63

9 天津地矿所同位素室. 同位素地质年龄数据汇编. 见: 天津地质矿产研究所所刊(11 号). 北京: 地质出版社, 1985. $211 \sim 245$

10 郭敬辉, 翟明国, 李永刚, 等. 晋軰蒙交界地区早前寒武纪变质杂岩同位素年代及其构造意义. 见: 钱祥麟, 王仁民主 编. 华北北部麻粒岩带地质演化. 北京: 地震出版社, 1994. 130 144

11 张宗清, 伍家善, 叶笑江. 阜平群下部太古代变质岩石的 REE, Rb $\mathrm{Sr}$ 和 $\mathrm{Sm}-\mathrm{Nd}$ 年龄及其意义. 地球化学, 1991(2)：118 126

12 赵宗溥. 中朝准地台前寒武纪地壳演化. 北京: 科学出版社，1993. 123 124

13 Huang X. SmrNd isotope study of early Archaean rocks, Qianan, Hebei province, China. Geochim Cosmochim Acta, 1986, 50: $625 \sim 631$

14 乔广生，王凯怡，郭起风, 等. 冀东早太古代岩石 Smr Nd 同位素年龄测定. 地质科学, 1987( 1)：86 92

\section{北大西洋涛动和北太平洋涛动的演变 与 20 世纪 60 年代的气候突变}

\section{李崇银 李桂龙}

(中国科学院大气物理研究所 LASG 国家重点实验室, 北京 100080)

摘要 用英国 Hadley 中心的海平面月平均气压资料, 分析研究了北大西洋涛动 (NAO) 和北太 平洋涛动 $(\mathrm{NPO})$ 的年际变化特征以及它们与北半球 60 年代气候跃变的关系。结果表明, NAO 和 NPO 的振幅在 60 年代发生了明显的增大, 其主要振荡周期也由 60 年代以前的 $3 \sim 4 \mathrm{a}$ 变成 了 $8 \sim 15$ a. 因此, 60 年代的气候跃变与 NAO 和 NPO 的异常有密切关系.

\section{关键词 北大西洋涛动(NAO) 北太平洋涛动(NPO) 气候突变}

很早人们就发现北大西洋地区的气压变化存在一种南北向尧羽尧板现象, 即当格林兰地区 气压升高时, 北大西洋副热带地区气压便降低, 反之亦然. 这种现象被称为北大西洋涛动, 简 称 $\mathrm{NAO}^{[1]}$, 它直接同大气半永久性活动中心冰岛低压和亚速尔高压的活动有关. 后来又发现 北太平洋地区也有类似的南北向翘尧板板式气压变化现象, 即北太平洋涛动, 简称 $\mathrm{NPO}^{[2]}$. 用计 算某格点与全球各个格点气压变化间的相关系数, 可以得到 NAO 型的 NPO 型遥相关 ${ }^{[3]}$.

关于 NAO 和 NPO 的演变, 一般都用“涛动指数” 的时间变化来描写. 以 $\mathrm{NAO}$ 为例, 涛动指 数可以用格陵兰附近地区 (某站或某区域平均) 与北大西洋副热带地区(某站或某区域平均) 的 气压差来表示. 本文将用目前在国外认为最好的一份月平均海平面气压历史资料(由英国 Hadley 中心收集整理), 来讨论 NAO 和 NPO 的年际变化特征. 同时, 为了避免用单站资料的局 地性影响, 增加分析结果的可靠性, 根据 Wallace 等人 ${ }^{[3]}$ 给出的 NAO 和 NPO 形势图, 以其高值 中心和低值中心区域为关键地区, 用较大范围的气压差来分别表示 NAO 和 NPO 的时间演变, 即用 $\left(25 \sim 40^{\circ} \mathrm{N}, 130 \sim 170^{\circ} \mathrm{E}\right)$ 地区与 $\left(50 \sim 65^{\circ} \mathrm{N}, 130 \sim 170^{\circ} \mathrm{E}\right)$ 地区平均的海平面气压差表示 